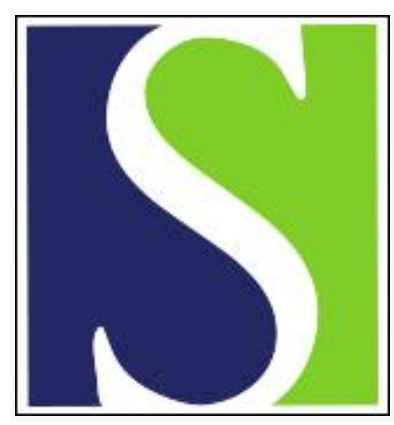

Scand J Work Environ Health 2005;31(5):343-351

https://doi.org/10.5271/sjweh.917

Issue date: Oct 2005

Occupational risk of affective and stress-related disorders in the Danish workforce

by Wieclaw J, Agerbo E, Mortensen PB, Bonde JP

Affiliation: Aarhus University Hospital, Department of Occupational Medicine, Denmark. jwiec@as.aaa.dk

The following articles refer to this text: $2009 ; 35(4): 294-300$;

2010;36(6):435-444

Key terms: affective disorder; Denmark; gender; mental disorder; occupational code; occupational risk; profession; relative risk; socioeconomic status; stress-related disorder; workforce

This article in PubMed: www.ncbi.nlm.nih.gov/pubmed/16273960

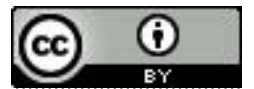




\title{
Occupational risk of affective and stress-related disorders in the Danish workforce
}

\author{
by Joanna Wieclaw, MSc, ${ }^{1}$ Esben Agerbo, MSc, ${ }^{2}$ Preben Bo Mortensen, MD, ${ }^{2}$ Jens Peter Bonde, MD'1
}

\begin{abstract}
Wieclaw J, Agerbo E, Mortensen PB, Bonde JP. Occupational risk of affective and stress-related disorders in the Danish workforce. Scand J Work Environ Health 2005;31(5):343-351.

Objectives A population-based, nested, case-control study was carried out to quantify the risk of affective and stress-related disorders according to occupation in the entire Danish workforce.

Methods All incident hospital patients and out-patients aged 18-65 years who received a first-time-ever diagnosis of an affective disorder (ICD-10, F 30-39) or stress-related condition (ICD-10, F 40-48) in Denmark from 1 January 1995 through 31 December 1998 were identified in the Danish Psychiatric Central Research Register $(\mathrm{N}=28$ 971). For each case, five randomly selected referents of the same age and gender were drawn from a 5\% sample of the Danish population ( $\mathrm{N}=144855)$. The occupation held 1 year before a person became a case was obtained from Denmark's Integrated Database for Labour Market Research. Occupation was classified according to the Danish version of the International Standard Classification of Occupations (ICD). Relative risks (RR) and $95 \%$ confidence intervals $(95 \% \mathrm{CI})$ for 25 occupational categories with clerical staff as the reference were calculated using a conditional logistic regression adjusted for sociodemographic covariates.

Results Eight occupations were associated with significantly elevated risks (RR range 1.20-1.58) among the women, while eight occupations were associated with a significantly reduced risk (RR range $0.50-0.76$ ) among the men. The risks were highest for the teaching (RR 1.58) and health (RR 1.53) professions. Only social workers and professionals caring for mentally and physically disabled persons faced an elevated risk irrespective of gender (women RR 1.72, 95\% CI 1.38-2.16; men RR 2.09, 95\% CI 1.38-3-15).
\end{abstract}

Conclusions Major depression and stress-related psychiatric disorders are related to occupation. Risk profiles vary strongly according to gender.

Key terms gender; mental disorder; occupational code; profession; relative risk; socioeconomic status.

Affective and stress-related psychiatric disorders are frequent, accounting for some $40 \%$ of incident psychiatric cases referred for in- or out-patient treatment in Danish hospitals. In 1995-2000, the incidence of first-time referral for affective disorders was $0.81 / 1000$ and for stressrelated disorders $0.99 / 1000$ person-years. Of the new cases for both diagnostic categories, 65\% were women (1).

Family history and female gender are well-known risk factors for depression (2-5). Some studies indicate a social gradient in the risk of depression with an increased risk in groups with low socioeconomic status (6-9). As occupation is strongly related to socioeconomic status, it can be hypothesized that occupational factors contribute to the development of mental health disorders. Indeed, increased risk of anxiety and depression has been associated with occupations with low skill levels and elementary tasks $(10,11)$. A few early studies have indicated that the prevalence of major depression, anxiety, psychological distress, and fatigue varies across professions (10, 12-15). Several human service professions and other occupational groups such as drivers, farmers, military personal, and fishery and forestry workers have been associated with an elevated risk of mental health problems (16-19). In the Norwegian Hordaland Health Study an inverse relationship was identified between occupational skill levels and anxiety and depression (10). A recent longitudinal study with a 12-25-year follow-up period showed that a negative attitude towards one's occupation was a strong predictor of recurrent depressive episodes (2). Our knowledge about the role occupation and psychosocial work conditions plays in the development of mental disorders, however, remains limited. Most studies are cross-sectional or exclusively based on self-reported exposure and outcome data and may, therefore, be subject to circularity in causal inferences (20-22).

1 Aarhus University Hospital, Department of Occupational Medicine, Denmark.

2 Aarhus University National Centre for Register-Based Research, Denmark.

Correspondence to: Ms Joanna Wieclaw, Department of Occupational Medicine, Aarhus University Hospital, Noerrebrogade 44, Building 2C, DK-8000 Aarhus C, Denmark. [E-mail: jwiec@as.aaa.dk] 
The present research takes advantage of the availability of reliable register data in Denmark and the concomitant opportunity to use independent measures of exposure and outcome. The study objective was to quantify the gender-specific risk of affective and stress-related disorders according to occupation.

\section{Study population and methods}

\section{National registers}

We conducted a nationwide population-based, nested, case-control study using Statistics Denmark's Integrated Database for Labour Market Research (IDA) (23) and the Danish Psychiatric Central Research Register (1).

IDA was developed in 1988-1990 mainly for research purposes. The database contains sociodemographic information on the entire Danish population and all workplaces. Both persons and workplaces can be monitored over time as from 1980. The IDA database aggregates various registers in Statistics Denmark, mainly the Population Registry and the Salary, Income, Employment and Tax Return registers. Since 1996 all companies and self-employed persons have been obliged to provide annual reports of employees' occupations to Salary Statistics using the Danish version of the International Classification of Occupations (DISCO 88). These data are validated against other registers at Statistics Denmark.

The Danish Psychiatric Central Register dates back to the 19th century and has been collecting data systematically since 1938. It was computerized in 1969 and includes all records of admissions and discharges to psychiatric hospitals or psychiatric wards in general hospitals in Denmark, the Faroe Islands, and Greenland. There are no private psychiatric hospitals in Denmark, and the Register therefore includes all admissions. As from 1995, the register also contains data on out-patient referrals.

Register data are collected in conformity with the highest academic standards to ensure maximum information accuracy and validity (24). Diagnoses rest on all available patient information and clinical observations made by the consultant in charge of the department where the patient is being treated. The latest edition of the International Classification of Diseases of the World Health Organization (WHO) is being used (since 1994 ICD-10). All entries into the Psychiatric Register are validated against clinical descriptions (25).

\section{Study cohort}

We created the study cohort by linking data from IDA and the Danish Psychiatric Central Research Register, using a unique person identifier (Central Person Register number), which is assigned to each person residing in Denmark. This number can be logically checked for errors, which makes it possible to identify people across different registers with very few errors.

The cases were selected among 18- to 65-year-old persons registered with a first-time-ever diagnosis of affective disorders (ICD-10, F 30-39) or stress-related conditions (ICD-10, F 40-48) from 1 January 1995 through 31 December 1998. The referents were selected from a $5 \%$ sample of the Danish population. We used the risk-set sampling method (26) to select five referents randomly for each case among all persons of the same age and gender at the time the case was identified. The resulting study cohort consisted of 28971 cases and 144855 referents. Similar sampling strategies and datasets have been used in other studies of psychiatric outcomes (27-29). The period of 1995-1998 was chosen to obtain complete data based on the latest edition of the WHO ICD-10 and to include persons who were treated as out-patients.

\section{Exposure measures}

Our main exposure measure was the occupation (DISCO code) held 1 year before a person became a case, and the five referents for each case were assigned the occupation held that year. The 1-year period was chosen to allow enough time for job-related risk factors to come into play. The DISCO88 classification system divides occupations into groups on the basis of level of education, skills required, and type of job function actually performed. Individual occupations are categorized at four-digit levels with increasing specification (narrower job categories) the more digit numbers. Classification of occupational groups at the DISCO 1-digit level reflects an increase in the level of education, skill requirements, and job responsibility (so-called skill discretion level): the lower the number, the higher the skill discretion level (major groups 1-9). In our study, we used the two-digit DISCO code level with the 27 submajor occupational categories, which are rather broad but which aggregate jobs in different sectors or industry. This level allowed us to analyze and compare the entire workforce and obtain complete data, since the recording of occupations at the third and fourth digit level is incomplete. Employment status was categorized into (i) currently employed persons (wage earner, selfemployment, owner, helping spouse), (ii) unemployed persons, and (iii) persons without attachment to the labor market (this category included students, retired persons, disability pensioners, and persons living on social benefits). Information was obtained on the extent of employment (full-time or part-time), number of years worked, age upon entering the labor market, and the extent of unemployment. 


\section{Outcome measures}

Outcome was defined as the first-ever diagnosis of an affective disorder, ICD-10 F 30-39, or a neurotic, stressrelated, or somatoform condition, ICD-10 F 40-48, given at the end of outpatient treatment or upon discharge from a psychiatric ward. We used broad diagnoses, which are believed to be more reliable (30), even if both diagnostic categories can, according to the WHO ICD10 classification, be divided into several subdiagnoses (F 30-39 for mainly several forms of depressive conditions and F 40-48 for various anxiety disorders).

In the following text, "depression" is used as a shorthand for affective disorders and "stress" for stress-related disorders.

\section{Statistical analyses}

The data analysis was performed with a conditional logistic regression using the PhReg procedure in the SAS version 8 statistical program package (31). We calculated relative risks for developing depression and stress disorder for 25 occupational groups using clerical staff (DISCO code 4) as a reference group. Furthermore, we computed the risks for the unemployed and persons without attachment to the labor market with the employed as a reference group. The $95 \%$ confidence intervals were calculated from the standard error of the risk estimate. Clerks were chosen a priori as references because they form a large occupational group $(\mathrm{N}=$ 16791 ) represented in almost all occupational sectors.

In order to test a hypothesis about the association between levels of skill discretion and our outcome measures, we calculated the relative risk for nine occupational groups at the DISCO 1-digit level.

The risk estimates were adjusted for gender, age, and time of exposure using the matched design. We adjusted also for marital status (single, not single), having children living at home (yes, no), socioeconomic status, as measured by the level of education (up to vocational or higher than vocational), and income level (EUR $\leq 27000$ per annum, EUR >27 000 per annum), duration of unemployment ( $\leq 2$ years, $>2$ years), and citizenship (Danish, not Danish). Finally, residence was included to account for possible regional differences (living in a town, living in a smaller town or in the countryside, living on Zealand (Denmark's largest island) or outside Zealand). All covariates were kept in the model irrespective of their effects and levels of significance. The analyses were stratified by gender.

\section{Results}

The gender-specific demographic characteristics of the 28971 cases and 144855 referents are shown in table 1.
Among the cases, 9662 (33\%) had a depressive disorder, while 19309 (67\%) had a stress-related disorder. A higher proportion of women than men was diagnosed with both disorders (62\% and $65 \%$, respectively). Depression was the most frequent among the elderly $(55 \%$ of the cases being $>40$ years old) and stress-related conditions were the most prevalent among the young $(66 \%$ of the cases being $<40$ years old). Case status was related to living alone, foreign citizenship, low income, low educational level, and unemployment and a lack of attachment to the labor market (table 1).

The relative risks of depressive and stress-related disorders according to the job held 1 year before the diagnosis are shown in table 2 for the women and in table 3 for the men. The job-related relative risk ranged from 0.50 to 1.58 , and the confidence intervals were narrow for most of the job categories owing to the large number of persons in the categories. The risk profiles varied strongly by gender. Compared with the clerical staff group, women faced a significantly elevated risk of depression in 8 of 25 jobs and a significantly elevated risk of stress-related conditions in 6 of 25 jobs. Only one job category, other associated professionals (mainly finance and business jobs, DISCO code 34), was associated with a reduced risk of stress. Elevated risks appeared mainly in human service professions such as teaching (DISCO codes 23 and 33) and health care (DISCO codes 22, 32 and 51), as well as among unskilled workers (DISCO codes 91 and 93). Furthermore, female general managers of enterprises with $<10$ employees (DISCO code 13) had an increased risk of both disorders.

Inversely, among the men, four occupations were associated with a reduced risk for depression, whereas eight professions were associated with a significantly reduced risk of stress relative to that of clerical workers. A reduced risk for both disorders was observed for corporate managers (DISCO code 12), scientists (DISCO code 21), mechanics (DISCO code 72), and men employed in finance (DISCO code 34), while the risk of stress was reduced among health professionals (DISCO code 22), technicians (DISCO code 31), and those employed in agriculture and the construction industry (DISCO codes 61 and 71).

Given the chosen reference, the only job consistently associated with an increased risk for both types of disorders among both genders was teaching-associated professionals (DISCO code 33). A more-detailed analysis of specific jobs in this category (the 4-digit DISCO code, data not shown) showed that professionals caring for the mentally and physically disabled and social workers carried the highest risks (DISCO code 3330, adjusted risks, male depression RR 2.1 , 95\% CI 1.133.92; stress RR $1.9495 \%$ CI 1.10-3.42; female depression RR 1.6, 95\% CI 1.14-2.36; stress RR 1.8, 95\% CI $1.32-2.35$ ), followed by staff in kindergartens (DISCO 
Table 1. Socioeconomic characteristics of the study population. The risk ratios (RR) were adjusted for all other socioeconomic variables. $(95 \% \mathrm{Cl}=95 \%$ confidence interval)

\begin{tabular}{|c|c|c|c|c|c|c|c|c|c|c|c|c|}
\hline \multirow{3}{*}{$\begin{array}{l}\text { Socioeconomic } \\
\text { characteristic }\end{array}$} & \multicolumn{6}{|c|}{ Women } & \multicolumn{6}{|c|}{ Men } \\
\hline & \multicolumn{2}{|c|}{$\begin{array}{c}\text { Cases } \\
{[\mathrm{N}=18526} \\
(17 \%)]\end{array}$} & \multicolumn{2}{|c|}{$\begin{array}{c}\text { Referents } \\
{[\mathrm{N}=92630} \\
(83 \%)]\end{array}$} & \multirow[t]{2}{*}{$\begin{array}{l}\text { Adjusted } \\
\mathrm{RR}^{\mathrm{a}}\end{array}$} & \multirow[t]{2}{*}{$95 \% \mathrm{Cl}$} & \multicolumn{2}{|c|}{$\begin{array}{c}\text { Cases } \\
{[\mathrm{N}=10445} \\
(17 \%)]\end{array}$} & \multicolumn{2}{|c|}{$\begin{array}{c}\text { Referents } \\
{[N=52225} \\
(83 \%)]\end{array}$} & \multirow[t]{2}{*}{$\begin{array}{l}\text { Adjusted } \\
\mathrm{RR}^{\mathrm{a}}\end{array}$} & \multirow[t]{2}{*}{$95 \% \mathrm{Cl}$} \\
\hline & $\mathrm{N}$ & $\%$ & $\mathrm{~N}$ & $\%$ & & & $\mathrm{~N}$ & $\%$ & $\mathrm{~N}$ & $\%$ & & \\
\hline \multicolumn{13}{|l|}{ Marital status } \\
\hline Single & 8233 & 45 & 30248 & 33 & $1.7^{b}$ & $1.7-1.8$ & 5047 & 48 & 18930 & 36 & $1.5^{b}$ & $1.4-1.6$ \\
\hline Not single & 10244 & 55 & 62271 & 67 & 1 & & 5378 & 52 & 33260 & 64 & 1 & \\
\hline \multicolumn{13}{|c|}{ Number of children } \\
\hline No children & 10717 & 58 & 53146 & 57 & 0.9 & $0.9-1.0$ & 7348 & 70 & 33434 & 64 & 1.0 & $0.9-1.0$ \\
\hline$\geq 1$ children & 7809 & 42 & 39484 & 43 & 1 & & 3097 & 30 & 18791 & 36 & 1 & \\
\hline \multicolumn{13}{|l|}{ Education } \\
\hline Basic & 10737 & 58 & 44880 & 49 & $1.2^{b}$ & $1.1-1.2$ & 5445 & 52 & 21451 & 41 & $1.2^{b}$ & $1.1-1.3$ \\
\hline Vocational & 4897 & 27 & 29830 & 32 & 1.0 & $0.9-1.0$ & 3557 & 34 & 21312 & 41 & 1.0 & $1.0-1.1$ \\
\hline Higher & 2840 & 15 & 17757 & 19 & 1 & & 1424 & 14 & 9422 & 18 & 1 & \\
\hline \multicolumn{13}{|l|}{ Employment } \\
\hline Not employed & 1143 & 6 & 3767 & 4 & $1.6^{b}$ & $1.5-1.7$ & 611 & 6 & 1642 & 3 & $1.5^{b}$ & $1.4-1.7$ \\
\hline Retired & 6945 & 38 & 23520 & 25 & $1.7^{b}$ & $1.6-1.7$ & 2998 & 29 & 7931 & 15 & $1.7^{b}$ & $1.6-1.8$ \\
\hline Employed & 10438 & 56 & 65330 & 71 & 1 & & 6835 & 65 & 42648 & 82 & 1 & \\
\hline \multicolumn{13}{|l|}{ Income } \\
\hline$E U R \leq 27000$ & 14931 & 81 & 66128 & 72 & $1.4^{b}$ & $1.4-1.5$ & 6310 & 61 & 21998 & 42 & $1.7^{b}$ & $1.6-1.7$ \\
\hline EUR > 27000 & 3406 & 19 & 25258 & 28 & 1 & & 4063 & 39 & 29919 & 58 & 1 & \\
\hline \multicolumn{13}{|l|}{ Citizenship } \\
\hline Not Danish & 1244 & 7 & 4485 & 5 & $1.1^{b}$ & $1.0-1.2$ & 925 & 9 & 2438 & 5 & $1.3^{b}$ & $1.2-1.6$ \\
\hline Danish & 17282 & 93 & 88145 & 95 & 1 & & 9520 & 91 & 49787 & 95 & 1 & \\
\hline
\end{tabular}

a Adjusted for the remaining sociodemographic variables.

b Significanly increased risk.

code 3320 ) and preprimary education teachers (DISCO code 3310).

Whereas unemployment carried a moderately increased risk for depressive disorders (female RR 1.65, 95\% CI 1.41-1.94; male RR 1.20, 95\% CI 0.92-1.55) and stress-related disorders (female RR 1.64, 95\% CI 1.47-1.83; male RR 1.26, 95\% CI 1.05-1.52), absence of any attachment to the labor market was associated with the highest risks among both genders, when compared with those in employment (depression female RR 1.91 , 95\% CI 1.70-2.15; male RR 1.43, 95\% CI 1.151.77; stress female RR 2.09, 95\% CI 1.93-2.25; male RR $1.73,95 \%$ CI 1.48-2.01).

We observed no association between the risk of depression and stress and the level of skill discretion according to the DISCO 1-digit classification.

We also performed analyses of risk by jobs held 3 and 5 years before referral to the hospital for depression or stress (data not shown). The findings were comparable to the findings based on analyses of risk by job held 1 year before the referral. Again, the jobs within education, health, social service, and personal services (nursing assistant and cleaning) were related to an increased risk among the women. In the case of the men, we found an increased risk of stress among the machine operators, transport workers, and cleaners (for the occupation 3 and 5 years before the diagnosis), as well as increased risks among teachers and social and personal service workers according to job codes 5 years before the diagnosis. The analysis of the subgroups that had the same DISCO code for 3 or 5 years showed a consistent increase in risks among the female teachingassociated professionals and social workers only.

\section{Discussion}

Our results showed that the risk of developing affective or stress-related disorders varies across occupations and that the risk profile is strongly influenced by gender. Elevated risks were found for the women, whereas the men faced a reduced risk in several occupations when compared with clerical staff. The magnitude of the increase in risk was moderate and similar to that found in other studies $(3,10,11,15)$. For both genders the highest risks for both disorders were found among social workers, professionals caring for the mentally and physically disabled, and teaching staff at the preprimary education level. As expected, no attachment to the labor market was associated with a substantial risk of both disorders $(8,32)$. However, we were not able to conclude 
Table 2. Adjusted relative risk (RR) of the affective and stress-related disorders among women according to occupation classified by the two-digit DISCO code level. (DISCO = Danish version of the International Classification of Occupations, $95 \% \mathrm{CI}=95 \%$ confidence interval)

\begin{tabular}{|c|c|c|c|c|c|c|c|c|}
\hline \multirow[t]{2}{*}{ Occupational title or industry a } & \multicolumn{4}{|c|}{ Affective disorders } & \multicolumn{4}{|c|}{ Stress-related disorders } \\
\hline & All & Cases & $\mathrm{RR}^{\mathrm{b}}$ & $95 \% \mathrm{Cl}$ & All & Cases & $\mathrm{RR}^{\mathrm{b}}$ & $95 \% \mathrm{Cl}$ \\
\hline Armed forces (01) & 17 & 1 & 0.52 & $0.07-3.99$ & 71 & 8 & 0.97 & $0.46-2.04$ \\
\hline Senior officials (11) & 51 & 6 & 1.34 & $0.57-3.18$ & 82 & 5 & 0.58 & $0.23-1.45$ \\
\hline Corporate managers (12) & 222 & 23 & 0.99 & $0.63-1.56$ & 392 & 48 & 1.14 & $0.83-1.56$ \\
\hline General managers (13) & 458 & 77 & $1.42^{\mathrm{c}}$ & $1.09-1.85^{c}$ & 912 & 153 & $1.38^{c}$ & $1.14-1.67^{c}$ \\
\hline Science professionals (21) & 175 & 15 & 0.79 & $0.46-1.37$ & 383 & 35 & 0.83 & $0.58-1.20$ \\
\hline Health professionals (22) & 506 & 80 & $1.53^{c}$ & $1.16-2.02^{c}$ & 847 & 66 & 0.76 & $0.58-1.00$ \\
\hline Teaching professionals (23) & 1348 & 197 & $1.32^{\mathrm{c}}$ & $1.08-1.61^{c}$ & 2465 & 298 & $1.19^{c}$ & $1.02-1.38^{c}$ \\
\hline Other professionals (24) & 642 & 65 & 0.92 & $0.70-1.22$ & 1108 & 119 & 0.89 & $0.73-1.10$ \\
\hline Technicians \& associated professions (31) & 492 & 48 & 0.84 & $0.61-1.15$ & 1096 & 111 & 0.83 & $0.68-1.03$ \\
\hline Health-associated professionals (32) & 1661 & 235 & $1.23^{c}$ & $1.02-1.48^{c}$ & 3196 & 321 & 0.97 & $0.84-1.11$ \\
\hline Teaching-associated professionals (33) & 1238 & 230 & $1.55^{\mathrm{c}}$ & $1.28-1.87^{c}$ & 2585 & 445 & $1.58^{\mathrm{c}}$ & $1.38-1.80^{c}$ \\
\hline Other-associated professionals (34) & 1482 & 156 & 0.98 & $0.80-1.19$ & 3000 & 305 & $0.86^{c}$ & $0.75-0.99 c$ \\
\hline Personal \& protective services (51) & 4404 & 731 & $1.36^{c}$ & $1.20-1.55^{c}$ & 9072 & 1416 & $1.20^{\mathrm{c}}$ & $1.10-1.31^{\mathrm{c}}$ \\
\hline Sales persons, demonstrators (52) & 997 & 128 & 1.06 & $0.86-1.31$ & 2448 & 235 & 1.10 & $0.96-1.27$ \\
\hline Skilled agricultural \& fishery workers (61) & 141 & 14 & 0.77 & $0.44-1.36$ & 239 & 24 & 0.81 & $0.53-1.25$ \\
\hline Extraction \& building workers $(71)$ & 76 & 11 & 1.14 & $0.60-2.20$ & 178 & 27 & 1.31 & $0.86-1.99$ \\
\hline Metal, machinery workers (72) & 35 & 6 & 1.47 & $0.60-3.59$ & 97 & 11 & 0.87 & $0.46-1.66$ \\
\hline Precision, handcraft, printing (73) & 127 & 16 & 1.10 & $0.64-1.90$ & 286 & 27 & 0.95 & $0.66-1.39$ \\
\hline Other craft workers (74) & 108 & 17 & 1.21 & $0.71-2.07$ & 273 & 27 & 0.83 & $0.55-1.25$ \\
\hline Stationary plant operators (81) & 23 & 4 & 1.39 & $0.47-4.16$ & 43 & 7 & 1.50 & $0.66-3.43$ \\
\hline Machine operators, assemblers (82) & 919 & 137 & 1.19 & $0.96-1.46$ & 2028 & 243 & 1.02 & $0.88-1.19$ \\
\hline Drivers, mobile plant operators (83) & 49 & 5 & 0.78 & $0.31-1.98$ & 108 & 16 & 1.13 & $0.66-1.95$ \\
\hline Elementary sales, service occupations (91) & 1737 & 280 & $1.28^{\mathrm{c}}$ & $1.08-1.50^{c}$ & 3359 & 554 & $1.25^{\mathrm{c}}$ & $1.12-1.40^{c}$ \\
\hline Agriculture, fishery laborers (92) & 286 & 41 & 1.24 & $0.87-1.76$ & 361 & 24 & 0.65 & $0.43-1.00$ \\
\hline Other laborers (93) & 217 & 40 & $1.46^{c}$ & $1.02-2.10^{c}$ & 464 & 76 & $1.33^{c}$ & $1.02-1.72^{c}$ \\
\hline Clerical staff (4) & 4524 & 522 & 1.00 & . & 9659 & 1204 & 1.00 & . \\
\hline
\end{tabular}

a The DISCO code is shown in parentheses.

${ }^{b}$ RR values have been adjusted for marital status (single yes, no), having children (yes, no), level of education (up to vocational, higher), income level (EUR $\leq 27000 / E U R ~>27000$ per year, total level of unemployment ( $\leq 2$ years, $>2$ years), residence (town, province), nationality (Danish, not Danish)

c Significantly increased or decreased risk.

whether not being employed is a cause or a result of having mental health problems.

\section{Interpretation of the results}

If the observed associations reflect causal pathways between psychosocial work conditions and the development of mental disorders, several mechanisms can be hypothesized.

Demands and role conflict. Health, social care, and teaching occupations share several characteristics that may explain some of our results with respect to demands and role conflicts. These types of jobs are believed to be demanding (high intensity, high workload, high psychological demand, and high responsibility), but, at the same time, they allow for a high level of skill discretion, flexibility, and control over one's job performance. According to Karasek's demand-control-job-strain model, this combination is expected to promote employees' well-being $(33,34)$ and would not explain our findings. However, employees in these jobs may also experience role conflicts (eg, between a career and a figure of authority) and ambiguities (eg, problems with professional boundaries, decision making, limitless tasks), which are believed to have adverse health effects (35).

Effort-reward imbalance. The effort-reward-imbalance theory claims that emotional distress results from a lack of reciprocity between the efforts invested in the job and the gains obtained (36-38). Work in human service professions can be demanding, but rewards in the form of salary, esteem, and career opportunities may be perceived as somewhat limited. Teachers and persons caring for the disabled and socially disadvantaged, in particular, are believed to experience increasing work challenges, but, at the same time, they seem to be losing their status, a combination that may result in inadequate returns for effort invested (39). More work is needed to clarify if any of these risk factors are part of the causal web augmenting the risk for major psychiatric disorders.

Exposure to violence, threats and emotional labor. We found the risks of violence, threats and emotional labor to be highest among special education professionals of both genders. In Denmark and other Scandinavian countries, this professional group differs from other educational 
Table 3. Adjusted relative risk (RR) of affective and stress-related disorders among men according to occupation classified by the twodigit DISCO-code level. (DISCO = Danish version of the International Classification of Occupations, $95 \% \mathrm{Cl}=95 \%$ confidence interval)

\begin{tabular}{|c|c|c|c|c|c|c|c|c|}
\hline \multirow[t]{2}{*}{ Occupational title or industry a } & \multicolumn{4}{|c|}{ Affective disorders } & \multicolumn{4}{|c|}{ Stress-related disorders } \\
\hline & All & Cases & $\mathrm{RR}^{\mathrm{b}}$ & $95 \% \mathrm{Cl}$ & All & Cases & $\mathrm{RR}^{\mathrm{b}}$ & $95 \% \mathrm{Cl}$ \\
\hline Armed forces (01) & 246 & 25 & 0.63 & $0.40-1.00$ & 665 & 73 & 0.76 & $0.57-1.00$ \\
\hline Senior officials (11) & 79 & 12 & 1.05 & $0.55-2.02$ & 120 & 12 & 0.80 & $0.43-1.49$ \\
\hline Corporate managers (12) & 714 & 76 & $0.69^{c}$ & $0.51-0.94$ & 1014 & 88 & $0.66^{c}$ & $0.51-0.86$ \\
\hline General managers (13) & 870 & 123 & 0.81 & $0.62-1.06$ & 1348 & 210 & 0.86 & $0.78-1.18$ \\
\hline Science professionals (21) & 751 & 78 & $0.63^{c}$ & $0.46-0.87$ & 1270 & 108 & $0.65^{c}$ & $0.50-0.83$ \\
\hline Health professionals (22) & 283 & 51 & 1.14 & $0.78-1.66$ & 299 & 22 & $0.58^{c}$ & $0.36-0.92$ \\
\hline Teaching professionals (23) & 759 & 120 & 0.94 & $0.70-1.25$ & 1083 & 140 & 1.10 & $0.87-1.40$ \\
\hline Other professionals (24) & 606 & 88 & 0.92 & $0.68-1.25$ & 930 & 104 & 0.83 & $0.64-1.07$ \\
\hline Technicians \& associated professionals (31) & 631 & 78 & 0.78 & $0.57-1.06$ & 1088 & 107 & $0.70^{c}$ & $0.55-0.89$ \\
\hline Health-associated professionals (32) & 77 & 10 & 0.80 & $0.40-1.60$ & 166 & 16 & 0.66 & $0.39-1.14$ \\
\hline Teaching-assocciated professionals (33) & 217 & 49 & 1.35 & $0.91-1.98$ & 381 & 82 & $1.58^{c}$ & $1.19-2.11$ \\
\hline Other-associated professionals (34) & 1087 & 111 & $0.65^{c}$ & $0.50-0.86$ & 1687 & 184 & $0.76^{c}$ & $0.61-0.93$ \\
\hline Personal \& protective services (51) & 658 & 120 & 1.11 & $0.84-1.47$ & 1403 & 254 & 1.14 & $0.94-1.38$ \\
\hline Sales persons, demonstrators (52) & 325 & 44 & 0.81 & $0.56-1.18$ & 746 & 97 & 0.83 & $0.64-1.07$ \\
\hline Skilled agricultural \& fishery workers (61) & 760 & 123 & 1.00 & $0.76-1.32$ & 1066 & 81 & $0.50^{c}$ & $0.39-0.66$ \\
\hline Extraction \& building workers (71) & 1264 & 173 & 0.84 & $0.65-1.07$ & 2402 & 286 & $0.76^{c}$ & $0.63-0.92$ \\
\hline Metal, machinery workers (72) & 1528 & 192 & $0.78^{c}$ & $0.61-0.99$ & 2993 & 315 & $0.73^{c}$ & $0.61-0.87$ \\
\hline Precision, handcraft, printing (73) & 159 & 20 & 0.81 & $0.48-1.35$ & 249 & 30 & 0.80 & $0.53-1.20$ \\
\hline Other craft workers (74) & 225 & 40 & 1.18 & $0.79-1.75$ & 456 & 59 & 0.91 & $0.67-1.24$ \\
\hline Stationary plant operators (81) & 125 & 18 & 0.90 & $0.52-1.54$ & 215 & 33 & 0.98 & $0.66-1.47$ \\
\hline Machine operators, assemblers (82) & 759 & 120 & 0.96 & $0.73-1.26$ & 1609 & 254 & 1.11 & $0.92-1.35$ \\
\hline Drivers, mobile plant operators (83) & 781 & 107 & 0.83 & $0.63-1.10$ & 1438 & 256 & 1.18 & $0.97-1.43$ \\
\hline Elementary sales, service occupations (91) & 383 & 75 & 1.19 & $0.87-1.65$ & 727 & 136 & 1.05 & $0.83-1.33$ \\
\hline Agriculture, fishery laborers (92) & 60 & 5 & 0.43 & $0.17-1.11$ & 125 & 19 & 1.00 & $0.60-1.68$ \\
\hline Other laborers (93) & 664 & 88 & 0.74 & $0.55-1.00$ & 1359 & 230 & 1.04 & $0.85-1.27$ \\
\hline Clerical staff (4) & 869 & 143 & 1 & $\cdot$ & 1739 & 278 & 1 & . \\
\hline
\end{tabular}

a The DISCO code is shown in parentheses.

b The relative risks have been adjusted for marital status (single: yes, no), having children (yes, no), level of education (up to vocational, higher), income level (EUR $\leq 27000,>27000$ per annum), total level of unemployment ( $\leq 2$ years, $>2$ years) residence (town, province) and nationality (Danish, not Danish).

c Significantly increased or decreased risk.

groups thus designated in English terminology (ISCO code no 3330). Their tasks center on the provision of all-round care for physically and mentally handicapped children and adults, usually in live-in facilities, as well as re-socialization work with drug and alcohol addicts, criminals, and other marginalized and disadvantaged groups. Their job tasks are typically concerned with daily activities and care, as well as with social training, but not with teaching. Professionals in these jobs are exposed to health hazards in the form of violence and threats, and they have irregular workhours that may be responsible for adverse mental health effects (40). Caring for other people often requires hiding one's true feelings also, so-called emotional labor, while on duty, and this effort has been shown to be associated with several mental health problems, especially emotional exhaustion (41).

Low-status repetitive jobs. Increased risks (28-46\%) in cleaning and unskilled industrial jobs may be rooted in the labor intensive and externally controlled nature of such jobs, which also have a low status and are often socially isolated (42). In accordance with other studies, our results presumably reflect a combined effect of a low-status job and gender-specific factors $(10,11)$.

Selection mechanisms. It is plausible that certain kinds of jobs attract certain kinds of people who may be more susceptible to mental disorders. Thus personality traits like "overcommitment", which is believed to be more common among human service professionals than among other professionals, has been shown to be a risk factor for poor well-being, job stress, and depression (36, 43). On the other hand, psychological hardiness, sense of coherence, and self-efficacy are viewed as protective personality factors $(44,45)$. Equally, it is likely that people drop out of jobs that are too difficult to cope with because of mental health problems, and in some professional cultures (mainly industrial and construction settings) persons with mental health problems can be ill-tolerated, circumstances that may result in selection out of jobs (46).

\section{Gender differences}

Twice as many women as men were diagnosed with either an effective or stress-related disorder, and we found 
increased risks in traditional female occupations. It is possible that women are more susceptible to mental problems than men, but that remains to be proved. We are inclined to view our results as a combined effect of job factors and female gender. Even when employed in the same job, women and men may be assigned to different tasks and thus be exposed to different occupational hazards. For example, women may be performing tasks with a higher degree of intensive personal care, whereas men may be doing more administrative and physically demanding tasks. Equally, the effects of a given occupational exposure may differ, and men and women may, for example, react differently to violence and threats. Opportunities for coping with job strain may also be modified by gender differences related to the position held within an organizational hierarchy and the impact of work-home interface problems. We found, for example, that being a female manager carries a higher risk than being a male manager. In summary, our results may reflect the effects of a gender-segregated labor market $(3,47,48)$.

Differences in help-seeking patterns and in the availability of health services may also have affected our results. More women are employed in occupational settings that are part of or related to health services, and women are generally more inclined to seek medical assistance. This finding may explain why women are more often diagnosed, but not necessarily more affected by depressive and stress-related disorders $(49,50)$.

It is often difficult to determine the direction of the associations found, as there can be a question of the employees' mental health status affecting their perception of work characteristics (reverse causation) or there is interplay between both factors (reciprocal relation). However, in our study, the problem did not arise, as information about occupation (exposure) was collected objectively (register data) and independently of the effect data, with the diagnosis of depression or stress-related conditions the following year. Still, in order to rule out some of the presented alternative explanations, we need to explore the role-specific psychosocial work conditions play in the development of stress and depression.

\section{Methodological issues}

The strengths of our study lie in the nationwide followup design and the use of objective measures of exposure and outcome. However, there are also some limitations. We modeled risk in the various occupations relative to the risk among clerical staff members. This choice of reference group was arbitrary, and it reflects the lack of a natural reference group in this descriptive study. The different risk patterns for the women and the men may reflect the fact that the reference groups differed, namely, female clerks and male clerks. It is possible that male clerks tend to be employed in different organizations, have different positions within an organizational hierarchy, and perform different tasks than female clerks. It should be acknowledged that an elevated risk in one occupation could also be interpreted as a decreased risk due to protective factors in the reference occupation. For instance, the data do not provide clues to the question of whether working as a clerk carries a risk among men or whether working in several other jobs protects against affective and stress disorders. However, the striking differences in the occupation-related risk profiles of the men and women indicate that job-related factors are part of the causal web.

Classification of occupations based on DISCO codes has only recently been introduced into the IDA register, and information is obtained from a variety of sources. As of 1999, the reporting procedure has been functioning well within the public sector and in enterprises with $>10$ employees (23). Information reported before 1996 or with the use of other codes (eg, Danish occupational codes) at Statistics Denmark was "translated " into DISCO codes by a program developed for that purpose. However, the problem of missing values and some degree of misclassification may remain with respect to DISCO codes obtained before 1999 and for smaller enterprises. Even so, biased risk estimates will be a problem if the underreporting of job codes is related to case status. This possibility did not seem to apply in our study, as there were $10 \%$ missing values among the cases and $11 \%$ among the referents.

In addition, the question of multiple comparisons arises. We performed 100 comparisons, and, at the $95 \%$ confidence level, 5 of them would be expected to be significant at random. Therefore one should bear in mind that, among the 14 significant results in our study, onethird can be attributed to random effects.

In our choice of time frame, we applied the job held 1 year before the diagnosis of depression or a stressrelated condition in order to allow for job-related causal factors to come into play. There is no clear agreement in research findings on a proper interval for causal factors and the development of mental disorders (51). Exposure must precede the outcome, but little is known about the timing of exposure relative to outcome. Being diagnosed is a function of the time needed for depression and stress to develop as a consequence of jobexposure factors, as well as the time necessary for the symptoms to reach the intensity that requires specialized hospital psychiatric treatment. The specific time interval depends, in turn, on a combination of personal factors and the character of the occupational exposure. In our judgment, an a priori choice of a 1-year interval was appropriate Our analyses based on the jobs held 3 and 5 years before the diagnosis showed patterns similar to those of the analyses based upon the job held 
1 year before the diagnosis. Interestingly, we found increased risks among the men in service professions and some industrial professions. This finding may indicate that, at that time, it was more unusual for a man to work in these typically female professions, which in itself may be a strain factor, as well as the fact that work conditions in industrial jobs were tougher. These results provide some indication that people tend to stay in jobs despite health hazards. However, our data did not provide good opportunities to obtain proper cumulative occupational histories, and we can expect substantial misclassification problems when historical data are applied due to changes in the coding system.

Furthermore, admission data and broad diagnostic categories (heterogeneous effect) may be too crude to illustrate the association between occupation and mental disorders. There can be some degree of overlap between diagnoses of affective and stress-related disorders. However, the diagnoses used in our study were made by physicians specialized in psychiatry, usually senior ones, who are in charge of psychiatric treatment and, as such, are the most qualified available. An attempt to validate psychiatric diagnoses was beyond the scope of our research.

\section{Concluding remarks}

Our study indicates that there are occupational differences in the relative risk of affective and stress-related disorders. The risk profiles varied strongly according to gender. Risks were greatest among health care workers, teaching professions, and social workers, as well as among people with no attachment to the labor market. It is likely that these mental health patterns are related to gender, social class, and selection mechanisms. However, our data are compatible with the hypothesis that the contents and work conditions of jobs play a role in the development of mental disorders. Hypothesis-testing follow-up studies are needed to shed more light on the causal pathways.

\section{Acknowledgments}

This study was supported by a grant from the Danish Working Environment Council.

\section{References}

1. Det psykiatriske centralregister, tabel 3: førstegangsindlæggelser fordelt efter køn, alder ved indlæggelsen og aktionsdiagnose; hele landet (1999-2003) [The Danish Psychiatric Central Re- search Register, table 3: the first ever admission according to gender, age at adimission and diagnosis; whole country (19992003)][homepage on the Internet] . Risskov (Denmark): Department of Psychiatric Demography, Institute for Basic Psychiatric Research, Aarhus University Hospital. [cited 21 June 2004, available from: www.psychdem.dk/indexEng.htm.

2. Riise T, Lund A. Prognostic factors in major depression: a long-term follow-up study of 323 patients. J Affect Disord 2001;65(3):297-306.

3. Bildt C, Michelsen H. Gender differences in the effects from working conditions on mental health: a 4-year follow-up. Int Arch Occup Environ Health 2002;75(4):252-8.

4. Ezquiaga E, Garcia A, Pallares T, Bravo MF. Psychosocial predictors of outcome in major depression: a prospective 12month study. J Affect Disord 1999;52(1-3):209-16.

5. Kupfer DJ, Frank E. Role of psychosocial factors in the onset of major depression. Ann N Y Acad Sci 1997;807:429-39.

6. Ferrie JE, Shipley MJ, Davey SG, Stansfeld SA, Marmot MG. Change in health inequalities among British civil servants: the Whitehall II study. J Epidemiol Community Health 2002; 56(12):922-6.

7. Muntaner C, Eaton WW, Diala C, Kessler RC, Sorlie PD. Social class, assets, organizational control and the prevalence of common groups of psychiatric disorders. Soc Sci Med 1998;47(12):2043-53.

8. Lorant V, Deliege D, Eaton W, Robert A, Philippot P, Ansseau M. Socioeconomic inequalities in depression: a metaanalysis. Am J Epidemiol 2003; 157(2):98-112.

9. Stansfeld SA, Head J, Fuhrer R, Wardle J, Cattell V. Social inequalities in depressive symptoms and physical functioning in the Whitehall II study: exploring a common cause explanation. J Epidemiol Community Health 2003;57(5):361-7.

10. Sanne B, Mykletun A, Dahl AA, Moen BE, Tell GS. Occupational differences in levels of anxiety and depression: the Hordaland Health Study. J Occup Environ Med 2003; 45(6):628-38.

11. Griffin JM, Fuhrer R, Stansfeld SA, Marmot M. The importance of low control at work and home on depression and anxiety: do these effects vary by gender and social class? Soc Sci Med 2002;54(5):783-98.

12. Eaton WW, Anthony JC, Mandel W, Garrison R. Occupations and the prevalence of major depressive disorder. J Occup Med 1990;32(11):1079-87.

13. Muntaner C, Tien AY, Eaton WW, Garrison R. Occupational characteristics and the occurrence of psychotic disorders. Soc Psychiatry Psychiatr Epidemiol 1991;26(6):273-80.

14. Grosch JW, Murphy LR. Occupational differences in depression and global health: results from a national sample of US workers. J Occup Environ Med 1998;40(2):153-64.

15. Bultmann U, Kant IJ, Van den Brandt PA, Kasl SV. Psychosocial work characteristics as risk factors for the onset of fatigue and psychological distress: prospective results from the Maastricht Cohort Study. Psychol Med 2002;32(2):333-45.

16. Michie S, Williams S. Reducing work related psychological ill health and sickness absence: a systematic literature review. Occup Environ Med 2003;60(1):3-9.

17. de Croon EM, Blonk RW, de Zwart BC, Frings-Dresen MH, Broersen JP. Job stress, fatigue, and job dissatisfaction in Dutch lorry drivers: towards an occupation specific model of job demands and control. Occup Environ Med 2002;59(6):356-61.

18. Niedhammer I, Goldberg M, Leclerc A, Bugel I, David S. Psychosocial factors at work and subsequent depressive symptoms in the Gazel cohort. Scand J Work Environ Health 
1998;24(3):197-205.

19. Pflanz S, Sonnek S. Work stress in the military: prevalence, causes, and relationship to emotional health. Mil Med 2002;167(11):877-82.

20. Taris TW, Kompier M. Challenges in longitudinal designs in occupational health psychology [editorial]. Scand J Work Environ Health 2003;29(1):1-4.

21. Teschke K, Olshan AF, Daniels JL, De Roos AJ, Parks CG, Schulz M, et al. Occupational exposure assessment in casecontrol studies: opportunities for improvement. Occup Environ Med 2002;59(9):575-93.

22. Kasl SV. Measuring job stressors and studying the health impact of the work environment: an epidemiologic commentary. J Occup Health Psychol 1998;3(4):390-401.

23. IDA (Integreret Database for Arbejdsmarkedsforskning) databasen [IDA Research Database] [database on the Internet] . Kopenhagen: Statistics Denmark [11-5-2004; cited 21.06.2004]. Available from: http://www.dst.dk/Vejviser/dokumentation/Varedeklarationer/ Emnegruppe/Emne.aspx?sysrid=1013\&timespath=19|

24. Munk-Jorgensen P, Mortensen PB. The Danish Psychiatric Central Register. Dan Med Bull 1997;44(1):82-4.

25. Mortensen PB. The future of psychiatric case register studies. Epidemiol Psichiatr Soc 1997;6(1):21-3.

26. Borgan O, Langholz B. Nonparametric estimation of relative mortality from nested case-control studies. Biometrics 1993; 49(2):593-602.

27. Qin P, Agerbo E, Mortensen PB. Suicide risk in relation to socioeconomic, demographic, psychiatric, and familial factors: a national register-based study of all suicides in Denmark, 1981-1997. Am J Psychiatry 2003;160(4):765-72.

28. Agerbo E, Byrne M, Eaton WW, Mortensen PB. Marital and labor market status in the long run in schizophrenia. Arch Gen Psychiatry 2004;61(1):28-33.

29. Qin P, Agerbo E, Mortensen PB. Suicide risk in relation to family history of completed suicide and psychiatric disorders: a nested case-control study based on longitudinal registers. Lancet 2002;360(9340):1126-30.

30. Kessing LV. Validity of diagnoses and other clinical register data in patients with affective disorders. Eur Psychiatry 1998;13(8):392-8.

31. Allison P. Estimating Cox regression models with PROC PHREG: survival analysis using the SAS system: a practical guide. Cary (NC): SAS Institute Inc; 1995. p. 111-84.

32. Siegrist J. Reducing social inequalities in health: work-related strategies. Scand J Public Health 2002;Suppl 59:49-53.

33. de Lange AH, Taris TW, Kompier MA, Houtman IL, Bongers PM. "The very best of the millennium": longitudinal research and the demand-control-(support) model. J Occup Health Psychol 2003;8(4):282-305.

34. Mausner-Dorsch H, Eaton WW. Psychosocial work environment and depression: epidemiologic assessment of the demandcontrol model. Am J Public Health 2000;90(11):1765-70.

35. Sparks K, Cooper CL. Occupational differences in the workstrain relationship: towards the use of situation-specific models. J Occup Organ Psychol 1999;72:219-29.

36. de Jonge J, Bosma H, Peter R, Siegrist J. Job strain, effortreward imbalance and employee well-being: a large-scale cross-sectional study. Soc Sci Med 2000;50(9):1317-27.

37. Ostry AS, Kelly S, Demers PA, Mustard C, Hertzman C. A comparison between the effort-reward imbalance and demand control models [electronic paper]. BMC Public Health 2003;3(1):10. Cited 10 June 2004. Available from: http://www.pubmedcentral.nih.gov/ articlerender.fcgi?tool=pubmed\&pubmedid $=12636876$.

38. von dem KO, Siegrist J. Reported nonreciprocity of social exchange and depressive symptoms: extending the model of effort-reward imbalance beyond work. J Psychosom Res 2003;55(3):209-14.

39. Travers C. Stress in teaching: past, present and future. In: Dunham J, editor. Stress in the workplace past, present and future. London, Philadelphia: Whurr Publishers Ltd; 2001. p 130-63.

40. Laposa JM, Alden LE, Fullerton LM. Work stress and posttraumatic stress disorder in ED nurses/personnel. J Emerg Nurs 2003;29(1):23-8.

41. Zerbe WJ. Emotional dissonance and employee well-being. In: Ashkanasy N, Härtel CEJ, Zerbe WJ, editors. Emotions in the workplace: research, theory and practice. Westport (CT): Quorum/Greenwood; 2000. p 189-214.

42. Sparks K, Cooper C, Fried Y, Shirom A. The effects of hours of work on health: a meta-analytic review. J Occup Organ Psychol 1997;70:391-408.

43. Tsutsumi A, Kayaba K, Theorell T, Siegrist J. Association between job stress and depression among Japanese employees threatened by job loss in a comparison between two complementary job-stress models. Scand J Work Environ Health 2001;27(2):146-53.

44. Poppius E, Tenkanen L, Hakama M, Kalimo R, Pitkanen T. The sense of coherence, occupation and all-cause mortality in the Helsinki Heart Study. Eur J Epidemiol 2003;18(5):389-93.

45. Lambert VA, Lambert CE, Yamase H. Psychological hardiness, workplace stress and related stress reduction strategies. Nurs Health Sci 2003;5(2):181-4.

46. Marshall NL, Barnett RC, Sayer A. The changing workforce, job stress, and psychological distress. J Occup Health Psychol 1997;2(2):99-107.

47. Evans O, Steptoe A. The contribution of gender-role orientation, work factors and home stressors to psychological wellbeing and sickness absence in male- and female-dominated occupational groups. Soc Sci Med 2002;54(4):481-92.

48. Messing K, Punnett L, Bond M, Alexanderson K, Pyle J, Zahm S, et al. Be the fairest of them all: challenges and recommendations for the treatment of gender in occupational health research. Am J Ind Med 2003;43(6):618-29.

49. Moller-Leimkuhler AM. Barriers to help-seeking by men: a review of sociocultural and clinical literature with particular reference to depression. J Affect Disord 2002;71(1-3):1-9.

50. Eagles JM, Howie FL, Cameron IM, Wileman SM, Andrew $\mathrm{JE}$, Robertson $\mathrm{C}$, et al. Use of health care services in seasonal affective disorder. Br J Psychiatry 2002;180:449-54.

51. Kessing LV, Agerbo E, Mortensen PB. Does the impact of major stressful life events on the risk of developing depression change throughout life? Psychol Med 2003;33(7):1177-84.

Received for publication: 28 June 2004 